\title{
Os Símbolos de Informação Pública nos Setores do Lazer e Turismo: resultados empíricos
}

\section{The Public Information Symbols in the Leisure and Tourism Sectors: empirical results}

\author{
Sérgio Ricardo Fiori ${ }^{1}$
}

\begin{abstract}
Resumo
Atualmente a facilidade de comunicação e o rápido deslocamento permitem com que as pessoas usufruam de inúmeras atividades de lazer e turismo em diferentes escalas: dentro de casa, em sua cidade, estado ou país. O contexto faz com que os símbolos de informação pública se estabeleçam como agentes facilitadores de comunicação, sendo potencializados em locais que abrigam pessoas das mais diferentes nacionalidades e que, por sua vez, possuem limitações para se expressar em outros idiomas como em aeroportos, eventos internacionais e centros históricos. Deste modo, ressalta-se o grande desafio de estudos sobre o tema evidenciando a questão cultural e a problemática quanto a compreendê-los, aceitá-los. $\mathrm{O}$ artigo aborda de maneira breve alguns estudos teóricos, além de apresentar uma pesquisa empírica realizada com oitenta e dois símbolos de informação pública.
\end{abstract}

Palavras-chave: símbolo de informação pública; pictograma; comunicação; lazer; turismo.

\begin{abstract}
Nowadays the ease of communication and the fast transfer allow people to enjoy numerous activities of the leisure and tourism in different levels: in-house, in their city, state or country. The background causes the public information symbols to be established like facilitator agents of the communication, being leveraged in places where people from most different nationalities are sheltered, and, therefore, show limitations to communicate in foreign languages in airports, international events and historical centers. Therefore, it emphasizes the great challenge of studies about the subject revealing the cultural issue and the problematic as to know them and accept them. The article discusses briefly some theoretical studies besides presenting a empirical research with eighty-two public information symbols .
\end{abstract}

Keywords: public information symbols; pictogram; comunication; leisure; tourism.

\footnotetext{
${ }^{1}$ Geógrafo pela Universidade de São Paulo com mestrado e doutorado em Geografia Física pela mesma instituição, tendo se especializado em Cartografia Temática direcionada ao setor do Turismo. Membro do Grupo de Pesquisa Geografia, Cultura e Turismo - Departamento de Geografia da FFLCH/USP. Assessor acadêmico da Academia de Viagens e Turismo (AVT). Em 2010 iniciará pós-doc com o tema Cartografia e Multimídia pela Universidade Federal do Rio de Janeiro. Email: sfiori@usp.br.
} 


\section{Introdução}

No mundo contemporâneo fundamentado na tríade: indústria, urbanização e comunicação de massa, as pessoas em seu cotidiano e ao longo de toda a vida, deparam-se mesmo sem perceber, com os mais variados símbolos de informação pública, os quais estão presentes, por exemplo, na etiqueta das roupas, em produtos de limpeza, nos mapas e guias dos mais variados assuntos, manuais de aparelhos eletro-eletrônicos e placas de sinalização em geral (locais fechados, ambientes rurais e urbanos, estradas, entre outros).

A concepção dos símbolos voltados ao grande público está baseada nos pictogramas, os quais descrevem graficamente objetos, atividades ou conceitos por meio de desenhos figurativos, não-verbais devendo ser diretos, de fácil compreensão e auto-explicativos.

Em relação aos setores do lazer e turismo, Gerber, Burgen \& Stanton (1990) ressaltam que cada vez mais os símbolos de informação pública se estabelecem como um importante meio de comunicação. Por outro lado, Carneiro (2001, p.7) alerta sobre a falta de estudos e pesquisas que avaliem profundamente a implantação, o uso e a compreensão de pictogramas visando um sistema de sinalização turística ${ }^{2}$, o que se traduz em uma escassa bibliografia tanto no Brasil quanto no exterior.

O grande problema está em limitações que ocorrem tanto no plano cultural, quanto na falta de padronizações que organizem a sistematização internacional. Deste modo, muitas vezes um único pictograma moderno pode ser interpretado ou representado de formas diferentes. $\mathrm{O}$ resultado é que muitos símbolos acabam não sendo lembrados ou usados, e pior ainda, ao serem mal interpretados comprometem sua essência: a comunicação.

Assim, é extremamente necessário um esforço continuado que procure inventariar, ordenar, uniformizar e divulgar um sistema de sinalização turística que alcance o maior número de pessoas. E para que isso ocorra é preciso ponderar que o usuário só irá entender a mensagem quando o repertório disponibilizado pelo produtor for igual ou muito próximo ao que ele conhece. O repertório como explica Carneiro (2001, p.8 e 26) são coleções, compilações de itens de mesma natureza que, reunidos, conformam um conjunto ou estoque de símbolos conhecidos (uma espécie de vocabulário) utilizados por um ou mais indivíduos.

\footnotetext{
${ }^{2}$ Compreende todo sinal gráfico (lingüístico, pictórico ou misto) que promova a correta orientação do usuário em uma destinação ou equipamento de lazer / turístico (CARNEIRO, 2001, p.11).
} 
O artigo disserta sobre a importância de uma metodologia que desenvolva a eficácia da função sinalética direcionada aos símbolos de informação pública, demonstrando ainda os tipos e o processo de concepção dos pictogramas utilizados nos setores do lazer e turismo, os quais se destinam à comunicação social em larga escala. Posteriormente, apresenta-se uma análise empírica realizada entre os anos de 2003 e 2007, que reuniu uma grande quantidade de símbolos presentes em publicações sobre sistemas de sinalização, mapas e sites brasileiros e de outros países. O estudo pondera que é possível almejar uma certa homogeneidade quanto a concepção e uso de pictogramas, mesmo havendo a factual heterogeneidade intercultural.

\section{A Função Sinalética dos Símbolos: o pictograma}

Os primeiros pictogramas modernos surgiram no ano de 1895 e representavam o setor dos transportes. Todavia, é somente após a Primeira Guerra Mundial que se iniciam os estudos para o desenvolvimento de um sistema de comunicação preocupado em superar a fronteira da língua (SAMOYALT, 1997). A autora relata que o filósofo austríaco Otto Neurath, interessado pela linguagem dos signos, criou o movimento Isotype, sistematizando um conjunto de pictogramas que buscava transmitir a informação de forma clara, simples e nãoverbal.

Na segunda metade do século XX, citam-se alguns trabalhos relevantes como dos designers Masaru Katzumie, Otl Aicher e Adrian Frutiger que desenvolveram, por exemplo, um conjunto de símbolos informativos para os Jogos Olímpicos de Tóquio (1964), Munique (1972) e Montreal (1976), além dos aeroportos de Frankfurt e Charles de Gaulle, respectivamente em 1971 e 1974 (ERCO, 2005 e SAMOYALT, 1997).

Neste contexto, os pictogramas dispostos na fig. 1 objetivam a comunicação social, isto é, não privilegiam aquelas imagens que possuem apenas intenções ornamentais ou estéticas. Souza (1992, p.132) ressalta que as barreiras comunicativas podem ser trabalhadas através da concisão gráfica, densidade semântica e enfoque na funcionalidade. 

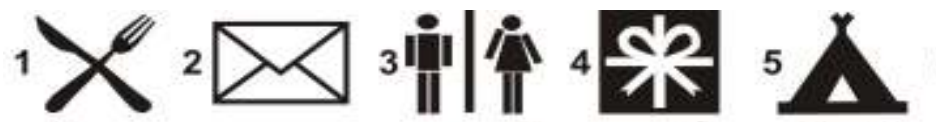

6
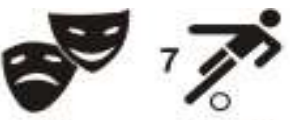

8
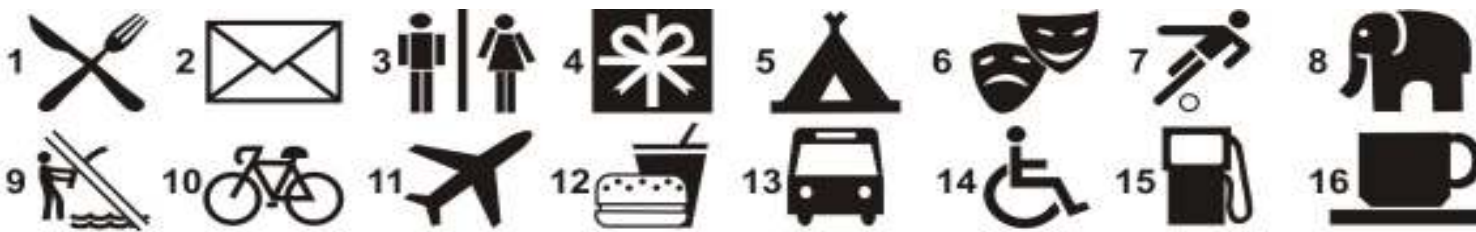

11.

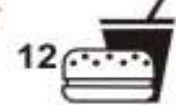

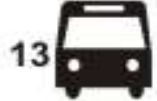

\section{4}

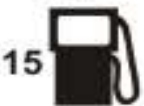

16

\begin{tabular}{|c|l|l|}
\hline $\begin{array}{c}\text { Forma } \\
\text { gráfica }\end{array}$ & \multicolumn{1}{|c|}{ O que representam ? } & \multicolumn{1}{c|}{$\begin{array}{c}\text { O que dizem? } \\
\text { Que mensagens comunicam? }\end{array}$} \\
\hline $\mathbf{1}$ & Garfo e faca & Restaurante \\
\hline $\mathbf{2}$ & Carta & Correio \\
\hline $\mathbf{3}$ & Homem, mulher & Porta de recinto (banheiro) \\
\hline $\mathbf{4}$ & Pacote decorado, presente & Local de compras (shopping) \\
\hline $\mathbf{5}$ & Tenda, cabana, barraca & Local para camping \\
\hline $\mathbf{6}$ & Duas máscaras (triste e alegre) & Teatro \\
\hline $\mathbf{7}$ & Jogando futebol & Evento esportivo, campo para esporte \\
\hline $\mathbf{8}$ & Elefante & Zoológico \\
\hline $\mathbf{9}$ & Homem pescando com barra diagonal & Proibido pescar \\
\hline $\mathbf{1 0}$ & Bicicleta & Ciclovia, aluguel de bicicleta \\
\hline $\mathbf{1 1}$ & Avião & Aeroporto \\
\hline $\mathbf{1 2}$ & Pão (hambúrguer) e copo (de suco, refrigerante) & Lanchonete, fast-food \\
\hline $\mathbf{1 3}$ & Ônibus & Estação rodoviária, parada de ônibus \\
\hline $\mathbf{1 4}$ & Homem em uma cadeira de rodas & Local acessivel a deficientes fisicos \\
\hline $\mathbf{1 5}$ & Bomba de gasolina & Local de abastecimento, posto \\
\hline $\mathbf{1 6}$ & Pires e xicara & Local onde se encontra café \\
\hline
\end{tabular}

Fig. 1 - O que representam e o que dizem essas formas gráficas?

Fonte: Adaptado de Souza, 1992, p. 2 e 5

Carneiro $(2001$, p.2) trata a concepção desse tipo de símbolo por ideograma, em outras palavras, é um desenho que representa uma idéia ou um elemento em particular, não havendo a necessidade da palavra. A figura $2 \mathrm{~A}$ apresenta um objeto concreto - o telefone - e um fato alimentação - representados por meio de pictogramas que estão no lugar do objeto, do fato. Moscardo (1999, p.53) complementa que quanto mais abstrata for uma imagem, maior será a necessidade de aprendizagem do seu significado (figura 2B). Consequentemente, o pictograma só terá sentido a partir do momento em que for reconhecido como sinal de comunicação (figura 2C). (SOUZA, 1992, p.148) 


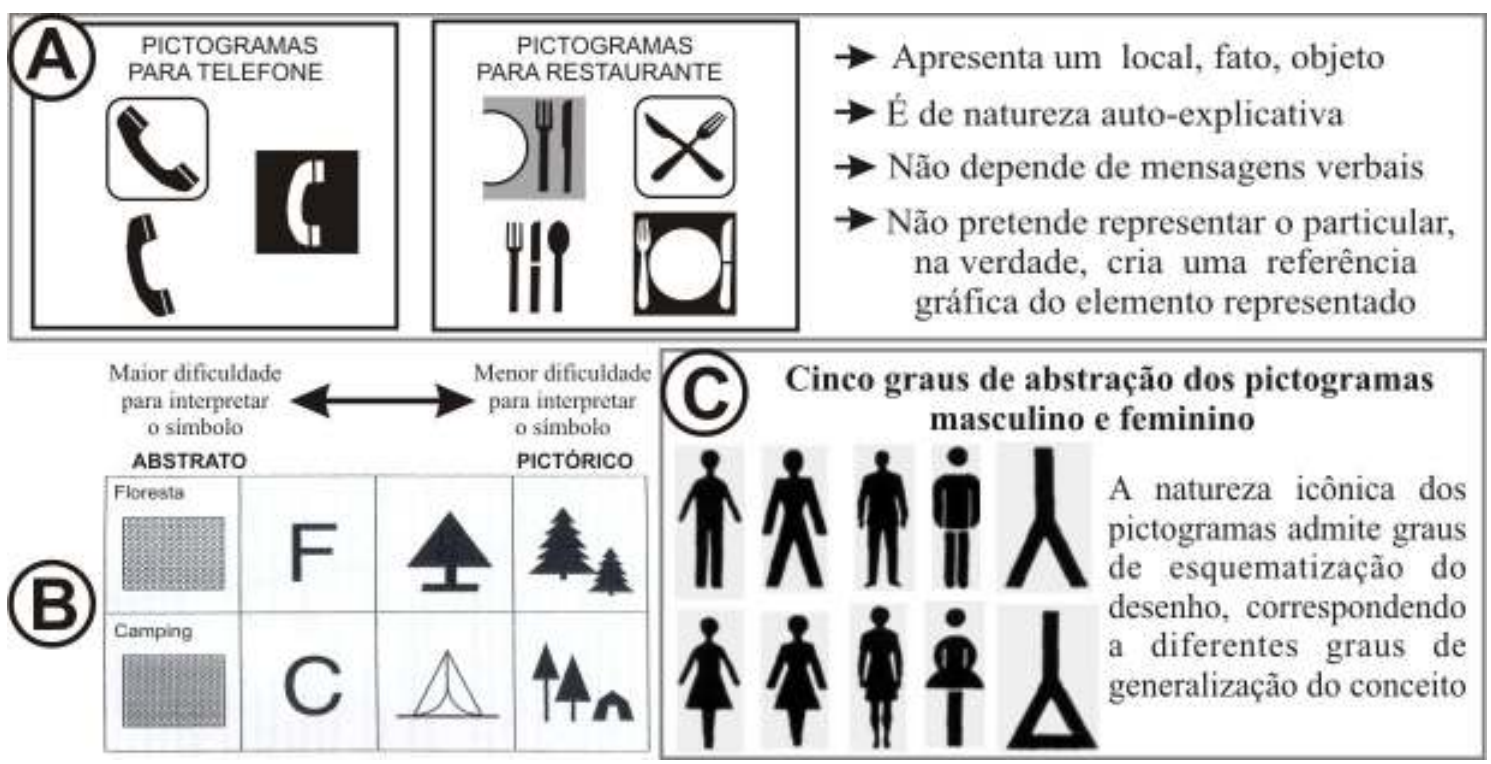

Figura 2 - Pictogramas e os graus de abstração da realidade

Fonte: Adaptado de Carneiro, 2001, p. 38; Souza, 1992, p. 141e 145; Moscardo, 1999, p.52.

Em suma, a compreensão, o uso e a implantação dos pictogramas resultam de imagens percebidas inicialmente na realidade concreta.

O processo perceptivo é dinâmico e arraigado ao comportamento humano, pois desde que se nasce e durante toda a vida o indivíduo recebe os mais variados estímulos e, pela inteligência, concentra sua atenção, tem expectativas, relaciona emoções e impulsos ao que a rodeia. A percepção sofre ainda, a influência direta de fatores individuais como, por exemplo, a motivação, a experiência e a aprendizagem (CABANELLAS, 1976, p.60).

Aliás, grande parte do processo de aprendizagem - instintivo ou intelectual - é visual, porém se observa que, na aprendizagem visual, não há um sistema estrutural arbitrário e externo semelhante à linguagem verbal ${ }^{3}$ (DONDIS, 1991, p.85-86).

Então, de que maneira a comunicação visual pode ser entendida, aprendida e expressa?

\footnotetext{
${ }^{3}$ Por meio da linguagem verbal as pessoas se alfabetizam em um processo dividido em etapas, contando com uma estrutura sintética e relativamente bem organizada. Primeiro se aprende um sistema de símbolos, representados por formas abstratas de determinados sons (grupo de símbolos sonoros): o alfabeto. Em seguida aprende a combinar as letras e de seus sons, formando as palavras, que se constituem como representantes ou substitutos das coisas, idéias e ações. Por fim, aprende-se uma sintaxe comum (língua específica: português, inglês, japonês) que limita o alfabetismo verbal e, mesmo em sua forma mais simplificada, representa uma estrutura dotada de planos técnicos e definições consensuais.
} 
Parte-se do pressuposto de que a informação visual é facilmente obtida por meio dos diversos níveis de experiência direta ao ato de ver e reconhecer (Dondis, 1991, p.86-87), como, por exemplo, um pássaro, uma casa, uma bicicleta, uma árvore, uma montanha, uma praia, etc. Essa capacidade ainda amplia o conhecimento da realidade-concreta do indivíduo, que generaliza toda uma espécie a seus atributos básicos, ou seja, o tipo pássaro, casa, homem, mulher, bicicleta são definidos em termos visuais elementares, sendo identificados em uma forma geral. Isto significa que todos os elementos compartilham referências visuais comuns dentro de uma categoria mais ampla - figura. 3.

As representações gráficas genéricas servem de apoio as imagens da memória, pois são graças a elas que se retiram alguns traços caracteristicos de objetos / elementos presentes no plano real-concreto, ou seja, aqueles aspectos que revelam as formas mais tipicas

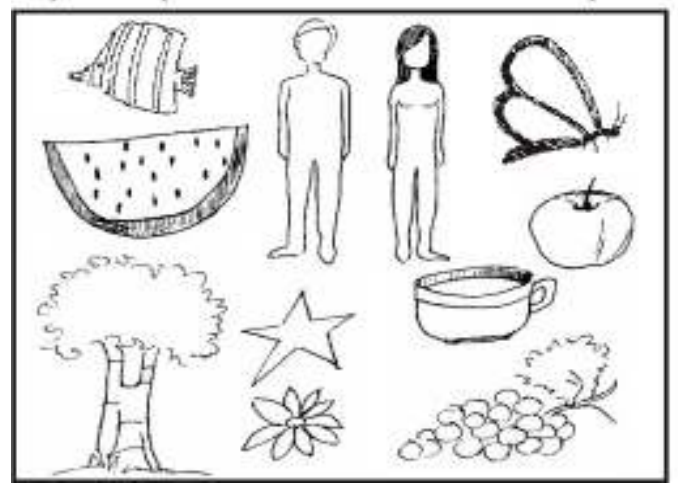

Outro exemplo: ao se falar em uma girafa, imediatamente vem à cabeça a imagem de um animal de pernas e pescoços longos, manchas, etc. Os três elementos gráficos abaixo mostram que apesar de seus itens atributivos serem um tanto vagos, eles são capazes de trazer semanticamente o conceito girafa. A mesma ideia é usada para compor os pictogramas

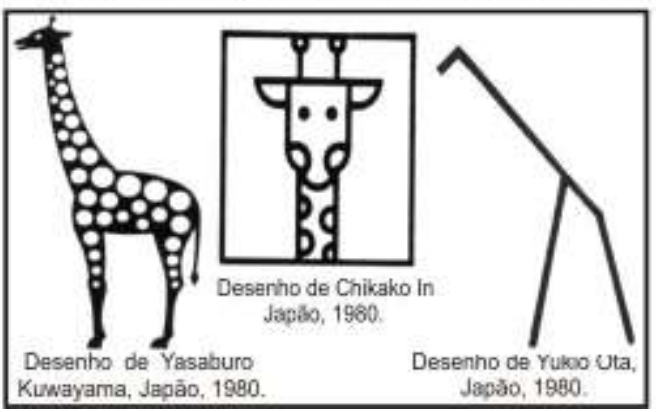

Figura 3 - Traços característicos do elemento representado: trabalhando o conceito Fonte: Fiori, 2007, p.52

Segundo Dondis (1991, p.19) uma coisa é certa, no geral o alfabetismo visual jamais poderá ser um sistema tão lógico e preciso quanto a linguagem verbal, pois sua estrutura tem uma lógica que o alfabetismo visual é incapaz de alcançar. Por outro lado, o autor (DONDIS, op.cit. p.186) expressa que a compreensão visual é um processo natural. O que precisa ser feito é um refinamento de percepção permitido pelo alfabetismo visual. O caminho não é o mesmo que o da linguagem verbal, onde existe um substituto que precisa ser reduzido de um 
estado para outro. No ato perceptivo visual ${ }^{4}$, uma maçã é a mesma coisa tanto para o inglês quanto para o francês, ainda que o primeiro a chame de apple e o segundo de pomme. Nessa situação, o que difere a linguagem verbal da comunicação visual é a possibilidade de evitar a ambiguidade das pistas visuais, tentando então, expressar as ideias de maneira mais simples e direta. Até porque, a sofisticação excessiva e a escolha de um simbolismo complexo podem trazer dificuldades na comunicação visual intercultural. A figura 4 ilustra que quando um símbolo é bem elaborado, o usuário consegue compreender boa parte da informação, mesmo não conhecendo o idioma finlandês ou húngaro.
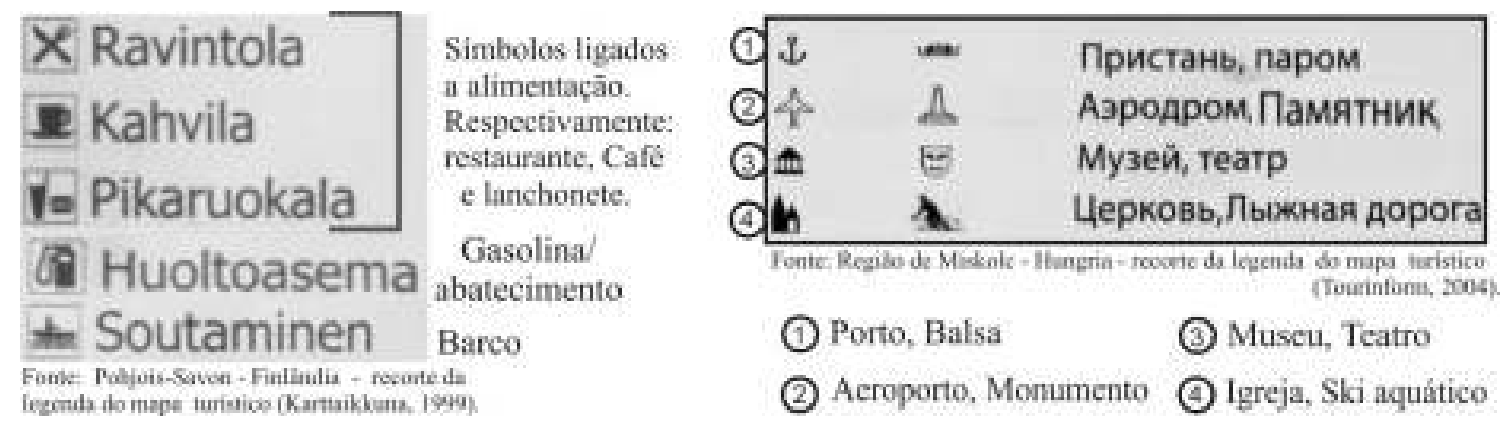

Figura 4-O desenho "fala" por si

Fonte: Adaptado de Fiori, 2007, p.60

Devido à inegável força da comunicação visual como meio de informação, torna-se cada vez necessário entendê-la com profundidade. Dondis (1991, p.185) alerta que não se poderá manter por muito mais tempo uma posição de ignorância diante do alfabetismo visual.

Posto isso, as etapas do processo de categorização para a produção de pictogramas compreendem as seguintes etapas (SOUZA, 1992, p.193):

\footnotetext{
${ }^{4}$ Pela percepção visual, a pessoa vivencia uma interpretação direta daquilo que está vendo. Todas as unidades individuais dos estímulos visuais interagem, criando um mosaico de forças saturadas de significado, exclusivo do alfabetismo visual e passível de ser diretamente absorvido com muito pouco esforço, se comparado à lenta decodificação da linguagem verbal (DONDIS, 1991: 188). Ressalta-se ainda, que a inteligência visual transmite informação em uma velocidade extraordinária, tanto que, estando os dados claramente organizados e formulados, a informação fica mais fácil de ser absorvida, retida e utilizada referencialmente.
} 
a) reconhecer atributos (gestuais ou formais) invariantes distintivos que um ser, objeto ou situação possuem para pertencer a esta ou àquela classe; b) valorar os atributos reconhecidos; c) selecionar os atributos mais significativos para uma correta identificação semântica do ser, objeto ou situação; d) traduzir os atributos selecionados para a linguagem gráfica, observando as normas ou padrões sintáticos já estabelecidos pelo uso.

No entanto, ao se buscar um princípio normativo para a criação de pictogramas, é comum surgirem várias versões para o mesmo conceito, logo, um pictograma que apresente pequenas diferenças gráficas não corre o risco de ter sua significação alterada (Figura 5A). Acrescentese que, embora o plano de representação do pictograma seja preferencialmente frontal, ainda existem os pictogramas longitudinais e, mais raramente, os em perspectiva (Figura 5B).

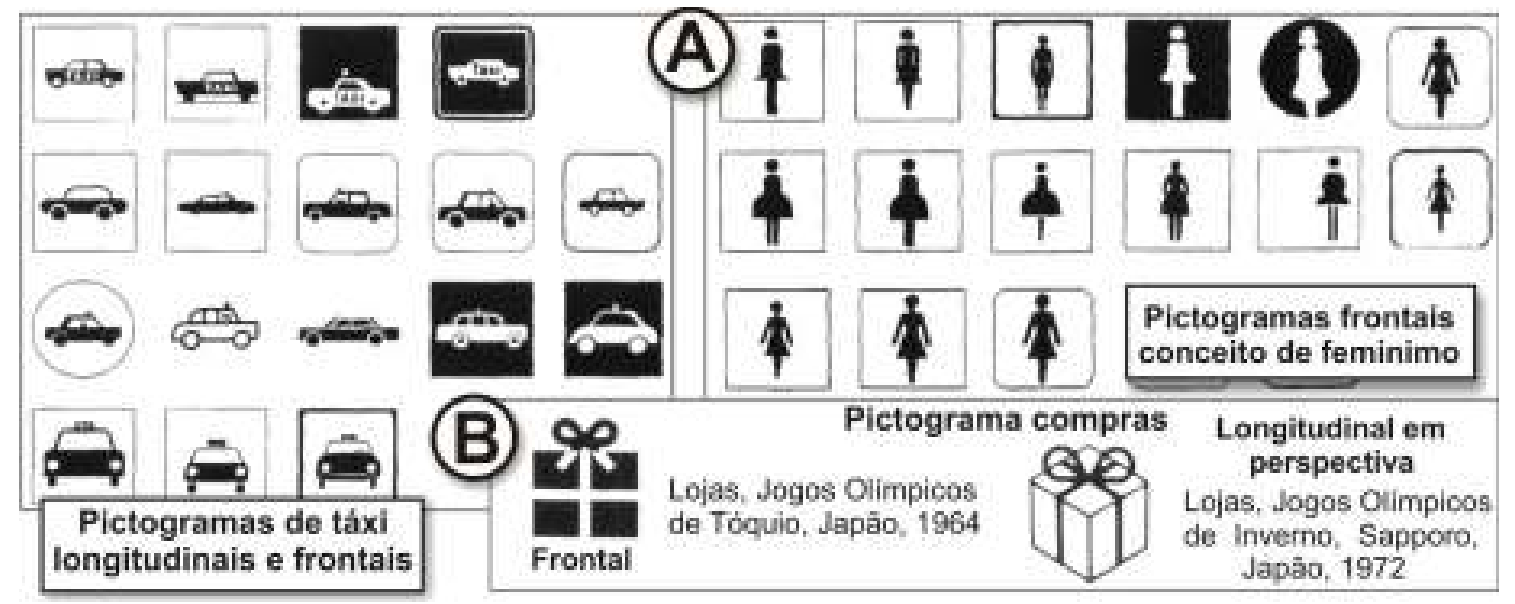

Figura 5 - Pictogramas: versões de um mesmo conceito

Fonte: Adaptado de Souza, 1992, p.182, 194 e 195

Uma outra abordagem alerta que todo pictograma pode se tornar obsoleto devido ao tempo. Até porque, qualquer sociedade passa por um processo dinâmico e natural de desenvolvimento, fazendo então, que alguns símbolos necessitem de uma readequação periódica. Gombrich (1991, p.134) e Carneiro (2001, p.4) citam que as representações são reflexo do processo evolutivo (Figura 6). 


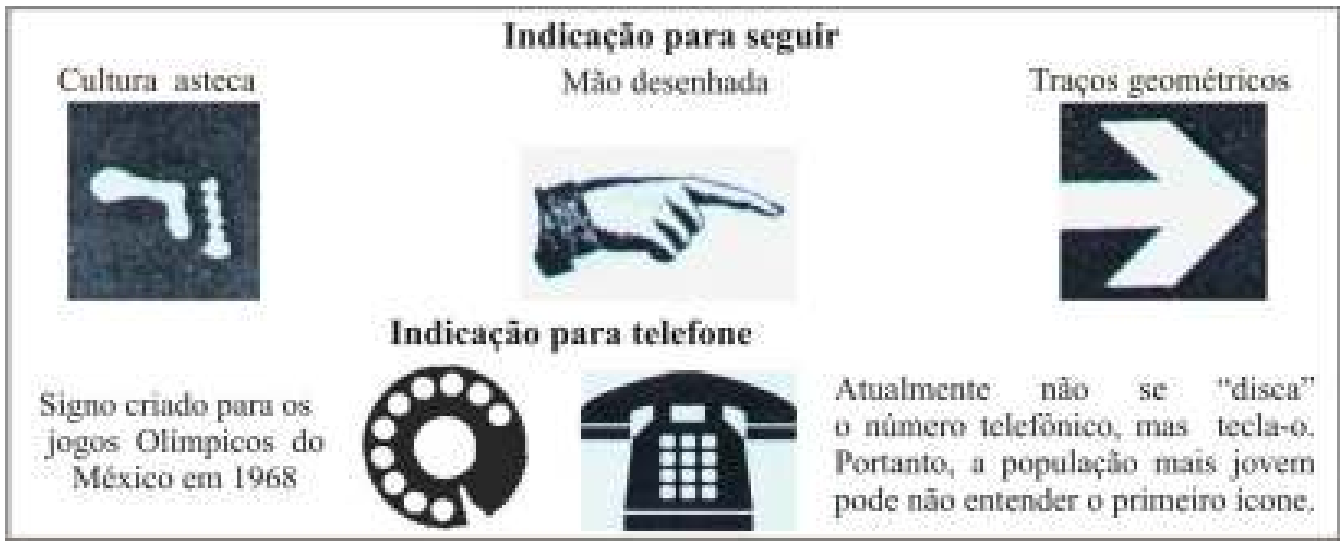

Figura 6 - As mudanças das representações gráficas ao longo do tempo

Fonte: Adaptado de Carneiro, 2001, p.4 e Gombrich, 1991, p.134

Samoyalt (1997) e Carneiro (2001, p.3) distinguem os pictogramas em três níveis (Figura7):

- Figurativo - caracterizado pela vocação mimética de sua imagem, ao representar o objeto, ação ou idéia por meio de um desenho que sugere a aparência do elemento representado. Informa de maneira imediata, não precisando de aprendizagem especial.

- Semântico - não é compreendido à primeira vista, exigindo um período de aprendizado. A imagem é trabalhada por meio de uma grafia simples, suficientemente clara e inteligível na relação representação-símbolo.

- O abstrato - não busca semelhança com o que representa, sendo um código entendido apenas por usuários que foram ensinados a utilizá-los. Contudo, quando incorporados no cotidiano das pessoas trazem a informação de maneira imediata e espontânea.
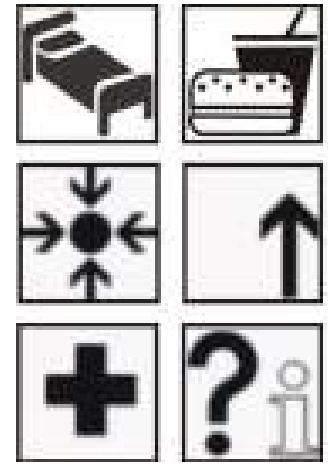
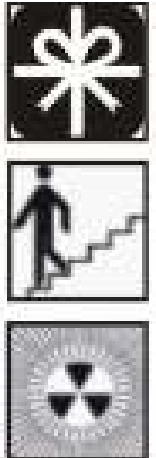

Figura 7 - Os três níveis de pictogramas

Fonte: ERCO, 2005 e Bruns, 2000, p. 30-31.
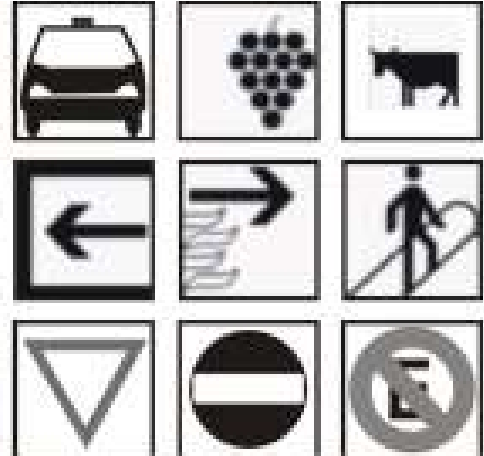

Semânticos

Abstratos

Figurativos

Abstratos 
Ao se abordar sobre a estrutura para a conformação de um sistema de sinalização turística, Beni (1998, p.39) classifica os principais grupos de necessidades e empresas no setor. De forma simplificada, os bens se dividem elementos materiais-imateriais e naturais-artificiais como monumentos, museus, praias, diferenças culturais (gastronomia, arte), entre outros. Já os serviços compreendem o receptivo (hotéis e outros tipos de acomodações), a alimentação (restaurantes, lanchonetes), o transporte, a administração pública (locais de informação turística, policiamento, primeiros socorros) e as atividades de recreação e entretenimento.

Buscando orientar o processo de criação e classificação dos pictogramas sinaléticos, Carneiro (2001, p.196) demonstra no esquema a seguir (figura 8) a estrutura inicial para um sistema de sinalização turística, a qual leva em conta três tipos de sinalizações: externa, interna e de uso comum. Todavia, é bom deixar claro que esse meio de informar e orientar sobre equipamentos, serviços e atrativos deve ser igualmente útil a todas as pessoas, sejam elas turistas ou moradores locais.

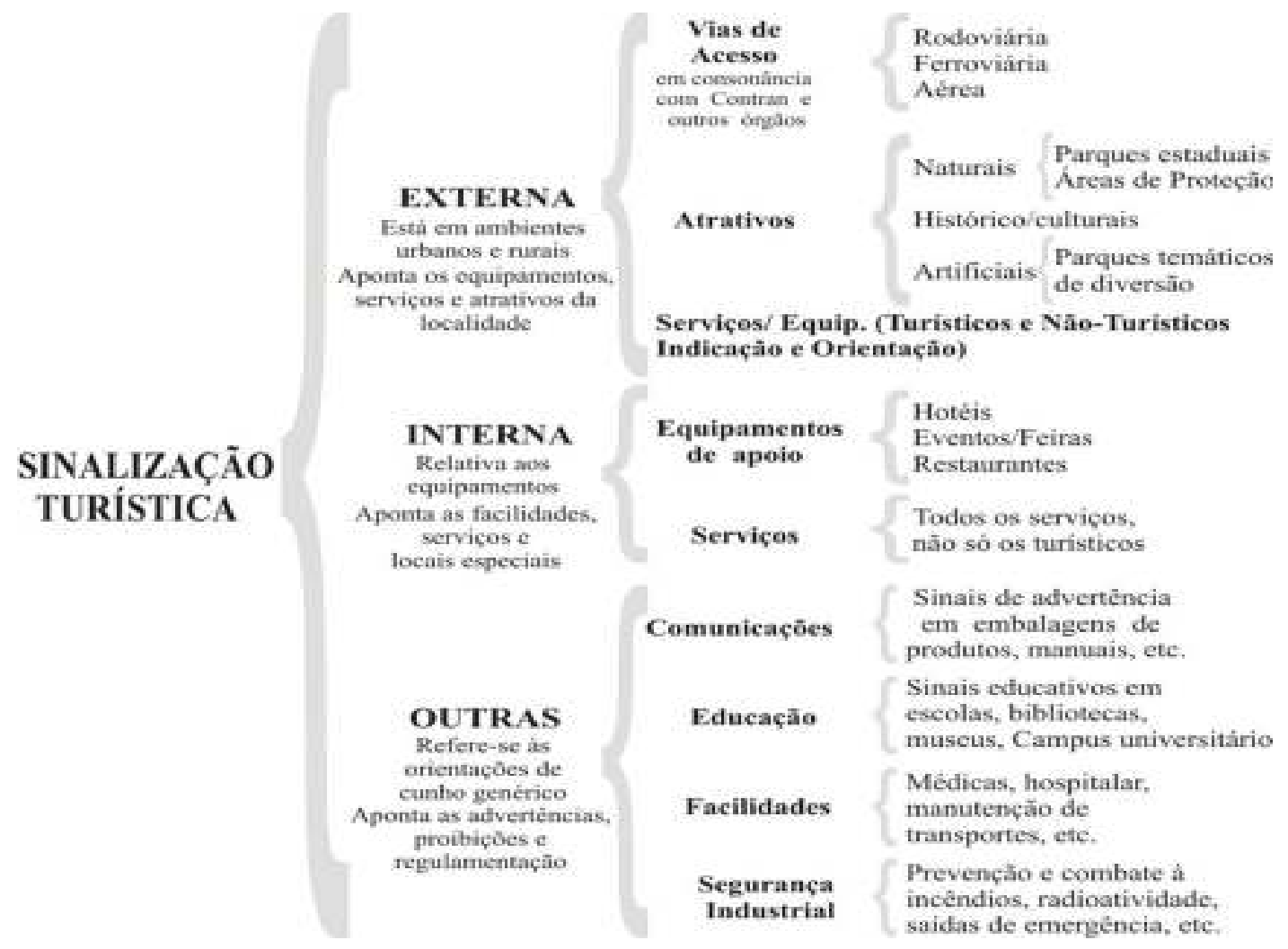

Figura 8 - Estrutura inicial de um sistema de sinalização turística

Fonte: Carneiro, 2001, p.197. 
Referenciando-se nesta estrutura (figura 8) são concebidos e avaliados uma grande quantidade de símbolos de informação pública, tendo como premissa básica a eficácia que procura a legibilidade e a inteligibilidade da mensagem. Desta maneira, tanto o desenvolvimento quanto a escolha para uso de um pictograma deve se guiar inicialmente pelas três dimensões de projeção do signo: a sintática, a semântica e a pragmática.

\section{Transformando a Imagem em Símbolo: as três dimensões de projeção do signo}

O signo é sempre um elemento que representa outro elemento: seu objeto, pois o signo só funciona como tal se carregar o poder de representar, substituir algo diferente dele. Consequentemente, o signo não é o objeto, apenas está no lugar dele, representando-o de um certo modo e numa certa capacidade. Ele pode ser interpretado através de experiências concretas, sentimentos ou pensamentos. Tudo dependerá da natureza e do potencial do signo, além das condições intrínsecas de vivência de cada pessoa (SANTAELLA, 1983, p.58). Os signos distinguem-se em duas partes:

- Significante - é o plano do conteúdo e transmite o aspecto concreto/material do signo.

- Significado - é o plano da expressão do elemento e transmite o aspecto abstrato/ conceitual do signo. O significado do signo não está nele próprio, mas nos conceitos ou imagens formadas na mente das pessoas. Isto nos faz supor, que o significado de um signo é outro signo, ou seja, uma imagem mental ou real, uma ação ou mera reação gestual, uma palavra ou mero sentimento de alegria, e assim por diante.

A junção dos dois aspectos leva a significação, que se define pela transmissão da informação por intermédio de um sistema lingüístico. A figura 9 ilustra que a comunicação só é conseguida quando o receptor-usuário associa ao sinal recebido a mesma intenção gerada pelo emissor. O processo é fundamentalmente baseado em duas condições: o canal deve ser rico o bastante para não ter ruídos; e o sinal deve fazer parte do repertório comum à fonte produtora e receptora (BERTIN, 1996, p.3). 


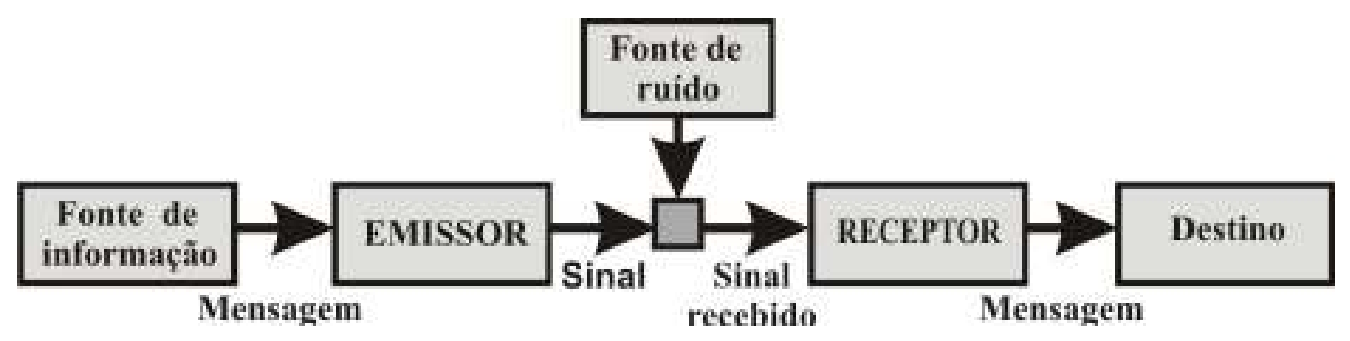

Figura 9 - Teoria da Comunicação

Fonte: Bertin, 1996, p.3.

O signo também é compreendido pelas dimensões sintática, semântica e pragmática, que em conjunto, auxiliam na estruturação e melhoramento da qualidade do repertório gráfico.

\subsection{A sintática: o estudo das relações dos signos com outros signos}

Preocupa-se com problemas relativos à forma da representação - como dizer ao usuário? estudando itens estruturais e técnicas de composição, os quais geram regras de formação e codificação visual de um elemento, além de examinar sua interação com outras representações (o conjunto de elementos) que também possuem regras referentes à linguagem e repertórios (CARNEIRO, 2001, p.33).

Souza (1992, p.72) afirma que o estudo da sintaxe se preocupada com a estrutura lógicogramatical da linguagem, caracterizada pelas qualidades materiais do signo em sua forma concreta e particular de existir. Entretanto, Dondis (1991, p.29) estabelece que a etapa da composição visual é vital a todo processo criativo, e é onde o comunicador visual exerce seu maior controle sobre o trabalho, tendo a oportunidade de expressar, em plenitude, o espírito de sua obra. No contexto do alfabeto visual, a sintaxe significa a disposição ordenada de partes (linhas, cores, proporções), não havendo regras absolutas. "O que existe é um alto grau de compreensão do que vai acontecer em termos de significado, se fizermos determinadas ordenações das partes que nos permitam organizar e orquestrar os meios visuais."

Existem duas regras sintáticas fundamentais: a formação, que promove combinações independentes, mas aceitas entre os signos de um sistema; e a transformação, que determina as combinações que podem ser obtidas por meio de outras combinações (SOUZA, 1992, p. 
73,74). Nesta relação, a autora ainda subdivide os signos de linguagem em três funções designadoras ou denotadoras, separando-os em decorrência do grau de expectativas relacionadas ao intérprete-usuário.

- Indéxico - chama a atenção do intérprete denotando individualmente um objeto. Como exemplo cita-se a palavra este, o signo gráfico da flecha ou o gesto de apontar com o dedo indicador.

- Caracterizador - denota uma pluralidade de coisas e tem sua designação explicada ou restringida em virtude da presença de outros signos que o especificam. Por exemplo, a palavra homem, as silhuetas de homens.

- Universal - denota qualquer coisa, pois tem uma significação universal. Cita-se a palavra algo, o pictograma de masculino ou feminino, de hospital, entre outros.

Normalmente, signos indéxicos, caracterizadores e universais se combinam, buscando um esforço para referenciar o objeto que está sendo aludido, para então determinar - com maior ou menor precisão - as expectativas do intérprete em relação às possibilidades semânticas dos signos utilizados. Portanto, na combinação dos signos existem aqueles que funcionam como dominantes e outros como especificadores (SOUZA, 1992, p.75). Na figura 10 o desenho de um homem em uma postura única funciona como um signo dominante. Já os complementos como os acessórios de cabeça e das mãos funcionam como especificadores das quatro profissões.

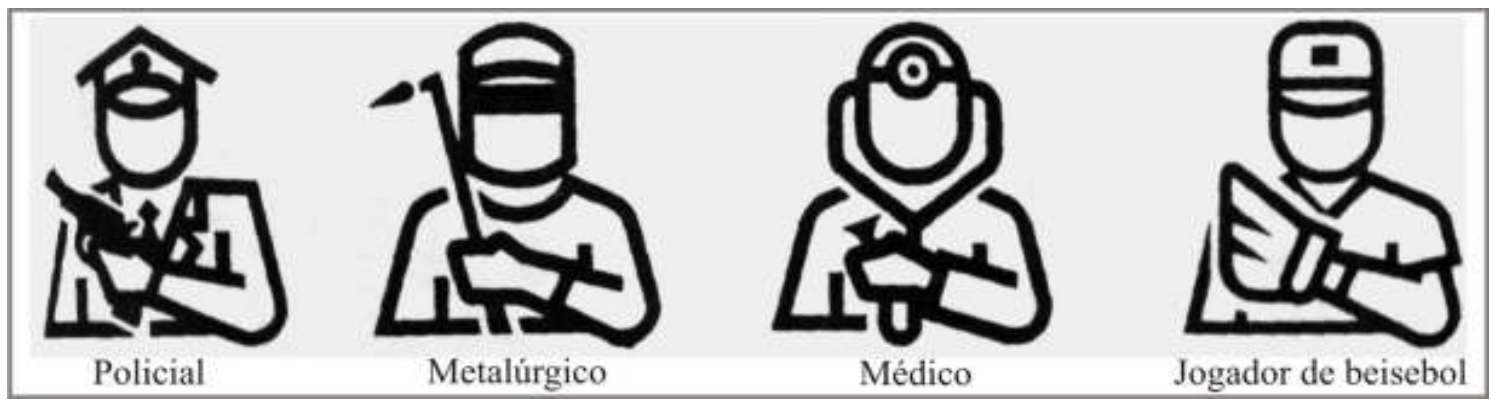

Figura 10 - Signos dominante e especificador Fonte: Souza, 1992, p.75. 


\subsection{A semântica: estudo das relações dos signos com os objetos a que se referem}

Segundo Souza (1992, p.46), é nesta dimensão que os profissionais em design gráfico deveriam despender noventa por cento de seu tempo. A dimensão se preocupa com problemas relativos ao conteúdo da representação, buscando desenvolver formas que se caracterizem sempre pelo menor ruído, ou seja, maior clareza possível. A pergunta semântica é: o que dizer sobre. Na verdade, as regras semânticas são muito mais estabelecidas por hábitos de conduta do que por proposições cientificamente provadas. Isso porque se configuram como modelos ou são aprendidas culturalmente e transmitidas por tradição (CARNEIRO, 2001, p.34 e SOUZA, 1992, p.76).

O desenvolvimento de um código é feito levando em consideração o meio de comunicação que transmitirá a mensagem (no caso, placas, mapas) a alguém (turista e também morador local) através de um canal (folha de papel, tela de computador, placas de sinalização). Consequentemente, a escolha não é aleatória devendo analisar a natureza da mensagem e as particularidades do canal e do meio de comunicação, para que, assim, os sinais ou unidades de significação (signos) sejam transmitidos da melhor maneira possível.

Oliveira (1977, p.23), Santaella (1990, p.63-68), Souza (1992, p.73-83) e Carneiro (2001, p. 31-36) apontam três tipos de relações semânticas ocorridas entre o signo e seu referente (objeto, elemento concreto): o ícone, o índice e o símbolo.

O ícone denota alguma(s) característica(s) do elemento representado, pois a imagem procura semelhanças gráficas àquilo que significa. Devido a sua capacidade de produzir relações de comparação entre o elemento concreto e o símbolo, a forma com que o ícone representa o objeto possibilita um alto poder de sugestão. Souza (1992, p.143) ressalta que as codificações icônicas são desde aquelas representações que possuem um grande número de propriedades visíveis de atributos do objeto (efeito de réplica, ilusão de realidade), até aquelas que apresentam um número reduzido de atributos os apresentando de maneira esquemática ou convencionalizada, como os símbolos de informação pública pictóricos - Figura 11.

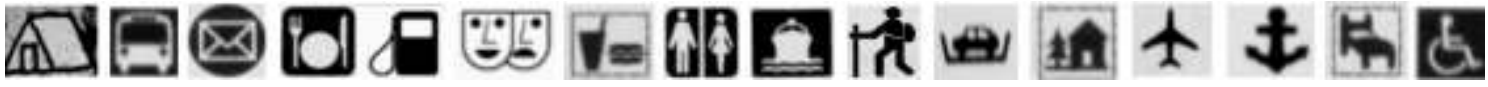

Figura 11 - O ícone: o desenho fala por si

Fonte: Recorte de vários mapas turísticos e sistemas de sinalização turística retirados de Fiori, 2007, p.186-192. 
Enquanto o índice (ou indicador) não apresenta propriedades de semelhanças com os objeto/idéia representados. É um tipo de signo onde o raciocínio do intérprete-usuário não ultrapassa a compreensão do signo como existência concreta, traduzindo simplesmente o que se vê, sem maiores implicações quanto a querer identificar, particularizar uma imagem. A figura 32 exemplifica que os pictogramas encerram-se neles mesmos - Figura 12.

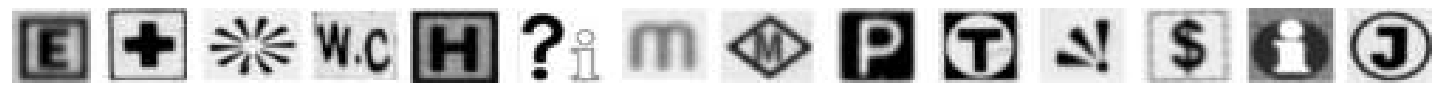

Figura 12 - O índice: o desenho não guarda semelhança direta com o que representa Fonte: Recorte de vários mapas turísticos e sistemas de sinalização turística retirados de Fiori, 2007, p.186-192

E finalmente o símbolo representa e designa os objetos similares a um modelo, tendo como referência normas e usos convencionais não-questionáveis, sendo simplesmente aceitos. Desta forma, a representação é portadora de uma lei que, por convenção ou pacto coletivo, determina que o signo represente o objeto. $\mathrm{O}$ símbolo então se caracteriza por representar as coisas de uma forma genérica, denotando uma espécie.

Há dois níveis distintos de convenção: a analógica (motivada) e a arbitrária. Na primeira, a significação cumpre seu papel à medida que o observador reconhece no signo as propriedades do elemento representado (Figura 13A). Na convenção arbitrária, a significação só é conseguida graças à existência de regras convencionalmente estabelecidas e adquiridas pelo aprendizado (Figura 13B). Já a figura 13C representa a contigüidade instituída, havendo uma regra entre o significado e o significante, logo, o intérprete recorre ao texto para entender o significado geral.
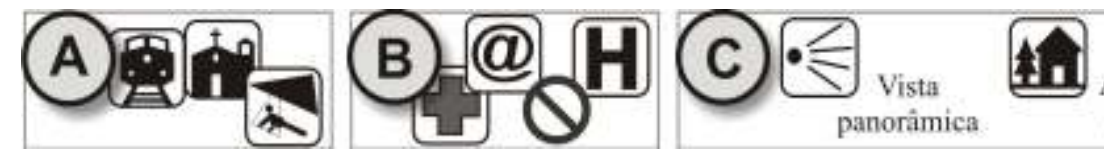

Albergue da juventude

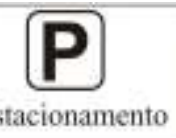

Figura 13 - Símbolo: o desenho desenvolvido através de normas convenções Fonte: Símbolos de informação público trabalhados em Fiori, 2007, p.249 


\subsection{A pragmática: estudo das relações dos signos com os usuários}

A dimensão se preocupa com o desempenho da representação - para que e qual usuário se dirige à mensagem - ao analisar as escolhas feitas durante o processo de elaboração de um signo (fenômenos psicológicos, biológicos e sociológicos), enfatizando ou eliminando qualidades e/ou atributos proporcionando o melhor entendimento ao usuário.

Esta dimensão introduz regras que trabalham em conjunto a dualidade: objetos representados e seus signos, de forma a causar uma mudança de comportamento nos usuários. Deve-se aqui levar em consideração que, quanto mais abstrata ou convencionalizada for à relação entre o signo e aquilo que designa, tanto maior será a necessidade dos hábitos a serem consolidados por algum tipo de aprendizado. A figura 14 exemplifica graus diferentes de abstração: o usuário só entenderá as mensagens a partir do conhecimento (habitus acumulado) anterior.

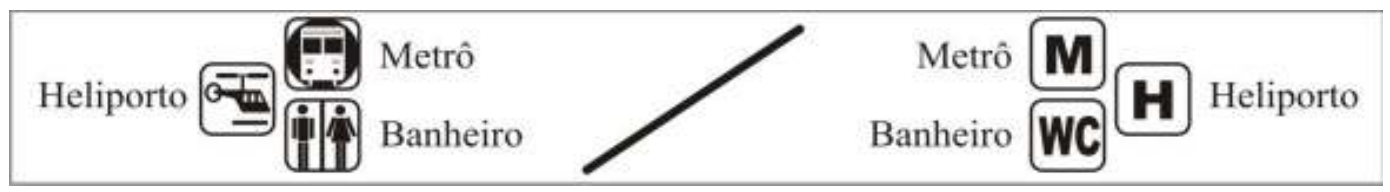

Figura 14 - Dois níveis de representação do mesmo símbolo

Fonte: Símbolos de informação público trabalhados em Fiori, 2007, p.249.

\section{Avaliação Empírica de 82 Símbolos de Informação Pública}

Como já ressaltado anteriormente, a procura de um sistema de sinalização direcionado aos setores do lazer e do turismo se divide em esforços para inventariar, ordenar, padronizar e divulgar um determinado conjunto de pictogramas, pelo menos no que se refere a ações, situações e locais de uso da maioria da população. Carneiro (2001:193) ratifica que, ser oficial, não é uma qualidade imposta pelos órgãos ou entidades, mas sim a condição legítima de utilização e inteligibilidade. A autora (CARNEIRO, op.cit. p.193) ainda aponta o $\mathrm{AIGA}^{5}$ como um importante instituto que realizou estudos

\footnotetext{
${ }^{5}$ O Instituto Americano de Artes Gráficas é uma associação sem fins lucrativos fundada em 1914. Nele se desenvolve um programa que inclui eventos, publicações, exposições e atividades educativas, com a finalidade de promover a qualidade e a excelência no terreno do desenho ou design gráfico. Entre os trabalhos o instituto
} 
complexos e sérios em relação, principalmente, à legibilidade "versus" distância e velocidade natural e artificial do usuário, frente ao símbolo, e as diretrizes de fontes e tamanhos de letras, figuras e setas.

Falando mais diretamente sobre a compreensão e aceitação do público ao pictograma em si,

Muehrcke (1986, p.83-84) assegura que os símbolos figurativos, os quais fazem uso maior da pictografia, são mais apreciados e compreendidos por crianças e usuários com pouca experiência em sistemas de sinalização em geral. Moscardo (1999, p.53) e Joly (1990, p.18) ratificam afirmando que quanto mais parecidos forem os símbolos com aquilo que representam - menor nível de abstração da realidade - mais fácil será interpretá-los, compreendê-los, aumentando a probabilidade de serem reconhecidos.

Fiori (2003 e 2008) então, recolhe, compara, trabalha graficamente (readequação de uma padronização estética) e prepara uma tabela com 82 símbolos de informação pública que tem como preocupação maior quantificar o grau de reconhecimento de cada pictograma. A escolha e o trabalho com os símbolos dispuseram da seguinte ordem:

$1^{\circ}$. Utilizar aqueles que já aparecem usualmente em mapas (nacionais e internacionais) e guias turísticos (como o guia Quatro Rodas), por apresentarem uma generalização pictográfica convencionalmente estabelecida na sociedade, facilitando assim, a descoberta do significado ao proporcionar um maior grau de familiaridade.

$2^{\circ}$. Tomar como referência e utilizar alguns dos símbolos propostos em uma pesquisa realizada em 1987 e 1989 por Stanton (apud GERBER, BURGEN \& STANTON,1990), que selecionou mapas turísticos da Austrália, Inglaterra, Suíça, Dinamarca, Nova Zelândia e Espanha. O intuito foi desenvolver uma série de pictogramas, tendo como base um modelo australiano para confecção de símbolos de informação pública (AS 2342), que é equivalente ao modelo britânico (BS 6034) e da Organização Internacional (ISO 7001). Tomou-se ainda como referência o trabalho de Clarke (1989), que selecionou duas séries de símbolos comumente usados e disponíveis em mapas turísticos

elaborou, por exemplo, sistemas gráficos de sinalização e programas de identificação para vários países (CARNEIRO, 2001, p.46). Veja alguns símbolos no endereço: http:www.aiga.org/content.cfm?contentID=147. 
pertencentes às instituições da Grã-Bretanha (Ordnance Survey) e dos Estados Unidos (Estate Publications).

$3^{\circ}$. Apoio valioso do trabalho de Carneiro (2001), que estudou ao longo de quatro anos sobre o tema da sinalização turística. A autora apresenta com detalhes os diretórios (ou sistemas) do $A I G A$ e Kuwayama ${ }^{6}$, fontes bibliográficas constantes nos sistemas oficiais brasileiros. Ao mesmo tempo, analisa outros sistemas de sinalização turística como o da Portland Oregon Visitors Association (POVA), das cidades de Navarra, Ibiza (Espanha) e Alentejo (Portugal).

Além disso, trabalha com outras fontes referenciais em publicações nacionais e internacionais.

Citam-se a empresa alemã ERCO e o sistema de sinalização das Olimpíadas de Sidney, Austrália, em 2000. Em relação as fontes nacionais, a autora optou por aqueles sistemas elaborados por órgãos oficiais de turismo, federal e estadual: o CONTRAN (Conselho Nacional de Trânsito), a EMBRATUR (Instituto Brasileiro de Turismo) e a Secretaria Estadual de Esportes e Turismo do Estado de São Paulo (SEET).

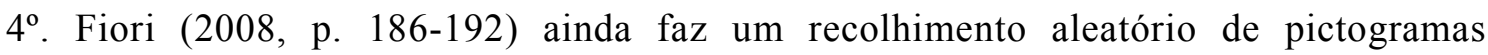
utilizados em várias partes do mundo. O pesquisador apresenta uma série de símbolos encontrados em publicações referentes a sistemas de sinalização turística, mapas turísticos e sites do Brasil e de outros países. O inventário demonstra que se pode almejar uma possível homogeneidade em relação aos pictogramas, mesmo havendo a factual heterogeneidade intercultural.

A partir da análise dessas referências, ao término do inventário se percebeu que:

- A mesma aparência gráfica de um pictograma é utilizada por diferentes culturas. Como é o caso, por exemplo, dos pictogramas de abastecimento (combustível), informação, café, hospital, aeroporto, natação, teatro, camping, entre outros.

\footnotetext{
${ }^{6}$ O diretório é uma publicação de uma empresa de Tóquio - a Kashiwashobo Publishing Co. Ltda. - intitulado Pictograms \& Typefaces of world, $\mathrm{n}^{\circ} 2$, editada por Yasaburo Kuwayama, que coletou e inventariou pictogramas ao longo de sete anos (1980/87) em 76 cidades de 39 países da Europa, Ásia e Américas (incluindo São Paulo e Rio de Janeiro). Em 1993, foi lançado o segundo diretório (CARNEIRO, 2001, p.65).
} 
- Implicações culturais puderam ser evidenciadas em alguns casos. Primeiro: todos os países já arrolados ilustram pictograficamente o item restaurante a partir de representações gráficas compostas por um garfo, uma faca, uma colher e/ou um prato. Contudo, no Japão - em mapas internos, não distribuídos aos estrangeiros - esse item é representado por meio de um rashi. Outro caso: o Brasil é o único país que não utiliza a letra $P$ (parking) para se referir a estacionamento, preferindo a letra $E$. Talvez a solução seja colocar o pictograma de um carrinho (redundância ao lado da letra), como utilizado em um mapa de Glasgow, Inglaterra. $\mathrm{O}$ mesmo fato acontece com os símbolos para Hotel. Uma observação final refere-se aos países do norte europeu (Alemanha, Finlândia, Suécia) que utiliza um olho para representar correio.

- Símbolos que se referem a atividades e atrações turísticas específicas e restritas a poucas destinações encontram uma maior dificuldade para serem compreendidos. O exemplo pode ser retirado dos pictogramas de arquitetura histórica, tipos de templos religiosos (igreja, mesquita, sinagoga), ou de atividades esportivas não muito conhecidas como: rafting, windsurfe ou rapel.

A figura 15 apresenta o conjunto de 82 pictogramas empiricamente avaliados. 


\begin{tabular}{|c|c|c|}
\hline Bondinho & Botel \\
\hline Teleférico
\end{tabular}

Fig. 15 - Apresentação dos 82 símbolos de informação pública

Fonte: Organizado por Fiori, 2007 
Fiori (2008, p.249 e 251) elabora questionários respondidos por 675 sujeitos, divididos em:

- Respostas dissertativas in loco - foram entrevistas 596 pessoas de quatorze estados brasileiros com faixa etária entre 20-60 anos. Neste caso, o sujeito deveria olhar o símbolo (um por um) e, logo em seguida, escrever em um espaço em branco, na frente do próprio símbolo, o que aquilo significava, ou seja, qual a primeira palavra que vinha a sua mente ao se deparar com aquele símbolo.

- Respostas alternativas via Internet (o site desenvolvido para a pesquisa compunham uma versão em português e inglês) - foram entrevistadas 79 pessoas, sendo 56 brasileiros 23 de outros países com faixa etária entre 20-60 anos. Nesse segundo caso, o sujeito via a relação dos símbolos, mas contava com uma grade numérica para cada símbolo que ia de um a cinco, relacionados, em uma escala, aos conceitos, de péssimo a ótimo. O sujeito, então, avaliava cada um dos símbolos.

A análise posterior das duas formas de questionários revela algumas respostas. Fiori (2007, p. 254-284) avalia que em geral, os pictogramas que recebem os maiores ou os menores níveis de acerto (respostas dissertativas) e de aceitação (respostas alternativas) são os mesmos. Também fica evidente que o símbolo em conjunto com o texto proporciona um auxílio importante à boa parte dos pictogramas, basta comparar a pontuação obtida pelos questionários: in loco e via Internet. No entanto, pode-se afirmar que outros são eficazes mesmo não utilizando texto complementar como os símbolos de aeroporto, restaurante, hotel, sorveteria, correio, supermercado, hospital, praia, telefone público, banco, vôlei, natação, futebol, tênis, golfe, basquete, asa delta, igreja, teleférico, táxi, abastecimento, lanchonete, e Internet. Ao olhar as respostas dissertativas dadas a esses pictogramas se percebem que os poucos entrevistados, ainda que não acertassem exatamente o símbolo, chegavam muito próximos do contexto-significado pretendido pelo produtor.

Já outros pictogramas, mesmo recebendo boa pontuação / aceitação, aproximam-se mais do que se quer informar quando acompanhados do texto verbal (símbolo + texto $=$ redundância). Portanto, o usuário vai ao texto para ler o que o pictograma significa, e posteriormente, não precisa mais do recurso para interpretar a informação, pois o símbolo de informação pública se faz claro e não é mais preciso voltar. Nesse caso se destacam os pictogramas de rodoviária, 
porto, metrô, heliporto / heliponto, estação ferroviária, balsa, estacionamento, praça / área para piquenique, acesso para deficiente físico, camping, pára-quedismo, balonismo, esqui na neve, cafeteria, mergulho, farol, danceteria / salão de dança, esqui aquático, surfe, caverna, teatro, hipismo, autódromo / cartódromo, ciclismo / ciclovia, cooper / corrida e biblioteca. Outros pictogramas como os que representam bondinho, parque de diversão, cachoeira, zoológico, trailer, jet ski, parque, delegacia, informação turística, playground, banheiro público, bar e cervejaria se encontram nessa relação mesmo recebendo uma pontuação menor, pois com o auxílio efetivo do texto, recebem um reforço para que haja uma boa interpretação do símbolo. Já nos pictogramas específicos - cuja significação requer o conhecimento da cultura, da atividade ou do serviço representado - o texto ao lado do símbolo é mais do que um tradutor, pois esclarece o que significa o elemento representado. Relacionam-se aqui os pictogramas: rapel / alpinismo, caiaque / canoagem, windsurfe, trekking / caminhada. Enquanto que nos símbolos Mesquita e Sinagoga são visíveis à necessidade de referências culturais para a compreensão do grafismo. Ao ser referenciado no Ocidente, o pictograma Igreja atinge altos valores de compreensão $(93,4 \%)$ e aceitação $(82 \%)$ nos dois questionários usados (in loco e site), seguido pelo pictograma Sinagoga, associado aos judeus, ao judaísmo, Estrela de Davi, Israel (41,3\% e 78\%). Já o pictograma Mesquita é associado, em sua grande maioria, a lua e a noite, apresentando uma menor compreensão $(23,8 \%)$ e aceitação (66\%).

Por fim, mencionem-se os pictogramas que se referem a conceitos amplos e / ou um traçado muito abstrato àquilo que se pretende informar. Nestes casos, além do texto como apoio, dever-se-ia pensar em alguma alteração gráfica no pictograma que pudesse aprimorar seu teor informacional. Enquadram-se ali os símbolos locação / aluguel de carro, shopping / compras, artesanato, oficina mecânica, guarda malas / guarda volumes, monumento, marina / atracadouro, bebedouro, pousada e barco / barco a vela. Todavia, quatro símbolos merecem consideração especial:

- Construção histórica - o produtor (Fiori, 2007) errou ao inserir, na mesma pergunta, dois símbolos que significavam a mesma coisa, mas em locais diferentes, isto é, a "torre" é usada para indicar construções históricas em alguns mapas europeus, enquanto a "casa" é utilizada em placas de sinalização turística no Brasil. 
- Albergue da juventude - a composição do pictograma é inspirada no símbolo utilizado pela organização dos albergues da juventude mundialmente conhecidos. Deste modo, o símbolo não merece correção, pois deve ter sido reconhecido na maioria das vezes apenas pelos usuários de albergues.

- Vista panorâmica - é um pictograma verdadeiramente problemático, como se pôde comprovar em duas pesquisas de Fiori (2003 e 2008). Os níveis de compreensão $(10 \%)$ e aceitação (54\%) são muito baixos.

- Museu - também merece reformulação: mesmo sendo um pictograma usado em todo o mundo e fortemente utilizado em placas de sinalização turística, apresenta um nível de compreensão e aceitação baixo (20\% e 65\%). Some-se ao problema, o fato de que mais de $50 \%$ dos entrevistados interpretaram o símbolo como circo.

\section{Conclusão}

É fato que no mundo contemporâneo à informação e as viagens (reais e virtuais) estão em constante crescimento. Abordando mais especificamente o setor do lazer e turismo, Uvinha (2007, p.57) relata um forte crescimento tanto no Brasil quanto em outros países. De acordo com a World Travel and Tourism Council, a estimativa para o futuro das viagens e do turismo é que represente $9 \%$ do total de empregos (diretos e indiretos) no mundo. Em termos reais, a probabilidade do crescimento é de 4,2\% ao ano no período compreendido entre 2007 e 2016.

$\mathrm{O}$ deslocamento em exponencial aumento e as várias maneiras de se comunicar (entre pessoas, placas, guias e mapas turísticos, Internet) demonstram uma tendência: os símbolos de informação pública, qualificados como um dos meios facilitadores da comunicação, tornamse cada vez mais importantes. Até porque, como alerta Carneiro (1997), as diversas línguas e culturas continuarão a existir paralelamente ao uso universal do inglês. Consequentemente é muito importante o estabelecimento de pictogramas que possuam um design eficiente e capaz de atingir o maior número de pessoas, independente de onde estejam.

Por outro lado, há poucos estudos no mundo buscando compreender, aplicar e propor formas de composições gráficas dirigidas à função sinalética dos símbolos, além da falta de pesquisas que analisem os atuais pictogramas. O artigo então, por meio do levantamento de materiais já 
existentes - sistemas e repertórios de sinalização turística - aliado a um trabalho empírico, demonstra que é possível desenvolver um mesmo pictograma que seja eficaz a uma grande parcela da população mundial. Todavia, alguns conjuntos sempre estarão sujeitos as características locais ou regionais. O desenvolvimento de símbolos de informação pública ainda deve privilegiar o uso das figuras pictóricas em detrimento da linguagem verbal.

\section{Referências}

AIGA. 2005. Disponível em: <http://www.aiga.org/content.cfm?contentID=147> consulta: 02/09/2005.

BENI, M. C. 1998. Análise estrutural do turismo. São Paulo: Senac.

CABANELLAS, I. 1976. Dibujo. 2.ed., Espanha: Editorial Magistério Español S.A.

CLARKE, L. M. 1989. An experimental investigation of communicative eficiency of point symbols on tourist maps. The cartographic Journal, v. 26, p.105-110.

BERTIN, J. 1996. Teoria da comunicação e da representação gráfica. Geocartografia, nº13, p.1-11.

BRUNS, C. B. 2000. Curso de formação de condutores. São Paulo: Tecnodata.

CARNEIRO, R.J.B. 2001. Sinalização turística: diretórios e sistemas nacionais e internacionais. 206 f. Dissertação (Mestrado) - Programa de Pós-Graduação em Ciências da Comunicação, ECA/USP, 2001.

; FONTE, N.D. 1997. Instrumento de promoção e estratégia de marketing. Turismo em Análise, v. $8, \mathrm{n}^{\circ} 1, \mathrm{p} .65-74$.

DONDIS, A. D. 1991. Sintaxe da linguagem visual. São Paulo: Martins Fontes.

ERCO. 2005. Disponível em <http://www.piktogramm.com> consulta: 02/09/2005.

FIORI, S. R. 2008. Mapas para o turismo e a interatividade - proposta teórica e prática. $310 \mathrm{f}$. Tese (Doutorado) - Departamento de Geografia, FFLCH/USP, 2007.

. 2003. Mapas turísticos: o desafio do uso da arte na era digital. 204 f. Dissertação (Mestrado) - Departamento de Geografia, FFLCH/USP, 2003.

GERBER, R.; BURDEN, P. \& STANTON, G. 1990. Development of public Information Symbols for tourism and recreational mapping. The cartographic Journal, v. 27, n 1, p.92-103.

GOMBRICH, E. H. 1991. La imagen y el ojo: nuevos estudios sobre la psicologia de la representación pictórica. 2.ed., Espanha: Alianza Editorial.

JOLY, F. 2005. A cartografia. $8^{\text {a }}$. ed., Campinas: Papirus.

MOSCARDO, G. 1999. Making visitors mindful: principles for creating sustainable visitor experiences through effective communication. Illinois: Sagamore Publishing. (Advances in tourism applications series)

MUEHRCHE, P. C. 1986. Map use: reading, analysis, interpretation. 2.ed. Wisconsin: JP Publications. 
OLIVEIRA, L. 1978. Estudo metodológico e cognitivo do mapa. IGEOG/USP. (Série Teses e Monografias)

SAMOYALT, T. 1997. Give me a sign: what pictograms tell us without words. New York: Viking.

SANTAELLA, L. O que é semiótica? 9.ed., São Paulo: Brasiliense, 1990.

SOUZA, S. R. M. 1992. Do conceito à imagem: fundamentos do design de pictogramas. $250 \mathrm{f}$. Tese (Doutorado) - Programa de Pós-Graduação em Ciências da Comunicação, ECA/USP.

UVINHA, R. R. 2007. Turismo e lazer: interesses turísticos. In: MARCELLINO, N. C. (Org). Lazer e cultura. Campinas: Alínea, p.45-64.

Recebido em: 09/02/2010

Aprovado em: 16/07/2010 